\title{
Effect of Therapeutic Massage in Cancer Patient: Suffering
}

\section{Márcia Lúcia Sousa Dias Alves ${ }^{1,2^{*}}$, Maria Helena de Agrela Gonçalves Jardim³, Bárbara Pereira Gomes 4}

\author{
${ }^{1}$ Otorhinolaryngology/Oncologyblood at the Hospital Dr. Nélio Mendonça, Funchal, Portugal \\ ${ }^{2}$ Abel Salazar Biomedical Sciences Institute, University of Porto, Porto, Portugal \\ ${ }^{3}$ Health Sciences Center, University of Fortaleza, Fortaleza, Brazil \\ ${ }^{4}$ School of Health, Porto, Portugal \\ Email: ^marcialves96@hotmail.com, hjardim@uma.pt, bgomes@esenf.pt
}

How to cite this paper: Alves, M.L.S.D., de Agrela Gonçalves Jardim, M.H. and Gomes, B.P. (2017) Effect of Therapeutic Massage in Cancer Patient: Suffering. Journal of Cancer Therapy, 8, 1095-1106. https://doi.org/10.4236/jct.2017.812094

Received: November 2, 2017

Accepted: December 3, 2017

Published: December 6, 2017

Copyright (c) 2017 by authors and Scientific Research Publishing Inc. This work is licensed under the Creative Commons Attribution International License (CC BY 4.0).

http://creativecommons.org/licenses/by/4.0/

Open Access

\begin{abstract}
People with oncological disease demonstrate, in addition to the side effects of the treatments, the future uncertainties and suffering, having this pathology an impact on self-image, in interpersonal relationships, the meanings and ways of life. We design the quasi-experimental study with the aim to evaluate the effect of the massage therapy on a sample of 31 suffering cancer patients, 16 of the experimental group and the control group 15. For the operationalization of the independent variable a protocol of massage therapy advocated by Tiffany Field was used and Hernandez-Reif uses the inventory of subjective Experiences suffering in illness (IESSD). The massage therapy was proved beneficial on psychological dimension $(p<0.001)$, physical $(p=0.001)$, existential $(p<0.001)$, relational partner $(p=0.005)$ and suffering $(p<0.001)$. Our purpose with this study is not only that health professionals use this intervention, and that these results encourage the scientific community, in carrying out future research in this pathology and other chronic diseases.
\end{abstract}

\section{Keywords \\ Oncology, Suffering, Massage}

\section{Introduction}

The pain reaches the integrity of the human being, encompassing the physical, but also the cognitive, social and emotional aspects [1]. The suffering is imputed to the domain of the body (physical) and soul (psychological), as well as the person in the biopsychosocial and spiritual. 
According to Pessini et al. [2], the pain is more than physical, affects the concept of "I", feels connected with you and the world. In the opinion of Gameiro [3], the meanings give meaning to events and conclude the cause of suffering, motivating and leading to the confrontation and for triggering emotional responses and attitudes in the processes of recovery and rehabilitation of disease. According to Gameiro [3] the meanings are associated with beliefs and convictions and are based on experiences experienced-external and internal.

The experience of being sick is parsed by a process and is conditioned by physiological factors, cognitive, emotional, relational and social-affective. To Mcintyre [4] this is a complex process that aims to integrate psicoafectiva of signs and symptoms with the cognitive assessment of threats, depending on this the meanings assigned by the person. Taking into account this scope the ICN States that are suffering long-term great pity feelings related to martyrdom and the need to withstand devastating conditions and the NCCN [5] defines suffering with a psychological (cognitive, behavioral State and emotional), social and/or spiritual that can interfere with the ability of the patient's adaptation in the face of cancer, the symptoms and the treatment. Cancer continues to be associated with the suffering, death and disability, triggering reactions of fear, hopelessness, anguish and dread [6].

The cancer sick can trigger psychological problems (anxiety, depression, fear, anger, rebellion, insecurity, loss, despair, humor and hope), social (isolation, stig$\mathrm{ma}$, changing roles, loss of control, loss of autonomy) and issues cancer-related (evolution of the disease, mutilation, treatments, pain, side effects, difficult relationship with the doctor) [7].

The nurses provide specific care focused on the patient, looking for help you in the realization of their projects and establishing an interpersonal relationship based on respect for the abilities of the person and the enhancement of your paper [8].

In nursing the pain is described as a global phenomenon that includes the person in your entirety, i.e. in its various dimensions, as it is the person who is suffering and not the body, the soul, the heart. As mention McIntyre [4] suffering has a multidimensional nature, since it is a biopsychosocial phenomenon involving the person in all your.

According to the CIPE, suffering is a negative emotion, because it encompasses feelings long associated with the martyrdom and the need of having to tolerate devastating conditions such as pain, psychological stress, bad reputation and injustice (NCI).

\section{Methodological Design}

Draw a level IV, quasi-experimental, in a population consisting of cancer patients followed up in consultation with the unit of pain Chronicles-hospital Oncology Day of RAM.

In this study it was included two groups of cancer patients, one whom we ap- 
ply the massage-experimental group $(\mathrm{n}=16)$ and another who does not apply this intervention control group $(n=15)$. Inclusion criteria were patients aged between 18 and 65 years including, in outpatient regimen, with medical diagnosis of cancer and cognitive ability of AutoFill of questionnaires. To this end applied to Mini Mental State Examination Scale. Exclusion criteria of the study at rush were patients with circulatory disorders, varicose veins, with inflammatory processes or fungal, fever or hyperthermia in treatment with chemotherapy, surgery, postradiation, poststroke or myocardial pós-enfarte, with bone pathology (fractures, recent twist), with hypertension, hemophiliacs, and with contagious diseases or skin.

For the operationalization of the dependent variable suffering applied inventory of Subjective Experiences of suffering in disease, this is an inventory of McIntyre with the Portuguese population that was validated by Gameiro in 1999. This inventory has five dimensions including the dimension of psychological suffering, the physical, the existential, relational and partner of the positive experiences of suffering.

\section{Results and Discussion}

With regard to the suffering and comparing the final evaluation with the initial, we note that there are statistically significant differences, in both groups, the psychological suffering, but in the experimental group the difference is more significant $(p<0.001)$ than in the $(p=0.003)$. The same situation is observed in the physical suffering with $p<0.001$ and $p=0.031$ respectively. In existential suffering $(p<0.001 ; p=0.252)$ and relational partner $(p=0.005 ; p=0.354)$ only if there were significant differences in the experimental group. The positive experiences of suffering significant difference occurs in the control group ( $p=$ $0.146 ; p=0.042$ ). In terms of global suffering, there are statistically significant differences in the two groups, however, are more pronounced in the experimental group ( $p<0.001 ; p=0.011$ ). Comparative analysis of the values found for the measures of central tendency we can say that the data show that patients undergoing therapeutic massage (experimental group) showed decreases more evident than the control group. These, in cases where the differences are significant, have revealed increased suffering. Based on these facts, we can conclude that patients experienced significant decrease massage subjects of suffering (Table 1).

In this study we found that both groups, on initial assessment, showed levels of psychological suffering above intermediary value 39 , namely: $\bar{x}=50.06$ in the experimental group and $\bar{X}=45.53$ in the control group.

There are studies that contradict these data, in particular Gameiro [9] shows an average for this dimension of suffering of 15.9, the Ramos [10] reports an average of 38.37 and Almeida [11] with an average of 37.1.

Similarly in Portugal, namely studies Paulo [12], reveals average levels greater than the intermediate scale values in this dimension $(\bar{x}=46.54)$. At the same time Sobral [13] report high values for the four dimensions of suffering, this being 
Table 1. Comparison of suffering among groups and between moments of evaluation.

\begin{tabular}{|c|c|c|c|c|c|}
\hline \multirow{3}{*}{$\begin{array}{c}\text { Group } \\
\text { Variable }\end{array}$} & \multicolumn{2}{|c|}{ Initial assessment } & \multicolumn{2}{|c|}{ Final assessment } & \multirow{3}{*}{ Test } \\
\hline & Experimental & 1 Control & Experimental & Control & \\
\hline & $\mathrm{n}$ & $\%$ & $\mathrm{n}$ & $\%$ & \\
\hline \multicolumn{6}{|l|}{ Psychological suffering } \\
\hline $\bar{x}$ & 50.06 & 45.53 & 38.88 & 48.47 & Exp. \\
\hline Md & 54.50 & 43.00 & 38.50 & 51.00 & $\mathrm{z}=-3.520$ \\
\hline $\mathrm{s}$ & 11.31 & 10.96 & 11.60 & 11.15 & $p<0.001$ \\
\hline $\mathrm{x}_{\min }$ & 29 & 28 & 15 & 28 & \\
\hline $\mathrm{x}_{\text {máx }}$ & 63 & 63 & 57 & 63 & Cont. \\
\hline $\mathrm{p}$ & 0.009 & 0.638 & 0.752 & 0.282 & $\mathrm{z}=-2.950$ \\
\hline Teste Mann-Whitney & $\mathrm{z}=-1.127$ & $p=0.260$ & $\mathrm{z}=-2.256$ & $p=0.024$ & $p=0.003$ \\
\hline \multicolumn{6}{|l|}{ Physical suffering } \\
\hline $\bar{x}$ & 22.94 & 21.07 & 17.00 & 22.07 & Exp. \\
\hline $\mathrm{Md}$ & 26.00 & 20.00 & 16.00 & 22.00 & $\mathrm{z}=-3.327$ \\
\hline $\mathrm{s}$ & 6.71 & 5.90 & 5.77 & 5.23 & $p=0.001$ \\
\hline $\mathrm{x}_{\min }$ & 8 & 12 & 7 & 13 & \\
\hline $\mathrm{x}_{\text {máx }}$ & 30 & 29 & 29 & 29 & Cont. \\
\hline $\mathrm{p}$ & 0.017 & 0.108 & 0.575 & 0.443 & $\mathrm{z}=-2.157$ \\
\hline Teste Mann-Whitney & $\mathrm{z}=-1.135$ & $p=0.256$ & $z=-2.302$ & $p=0.021$ & $p=0.031$ \\
\hline \multicolumn{6}{|l|}{ Existential suffering } \\
\hline $\bar{x}$ & 53.94 & 48.47 & 39.13 & 49.93 & Exp. \\
\hline $\mathrm{Md}$ & 55.00 & 49.00 & 39.00 & 51.00 & $\mathrm{z}=-3.520$ \\
\hline $\mathrm{s}$ & 11.73 & 12.12 & 10.15 & 10.32 & $p<0.001$ \\
\hline $\mathrm{x}_{\min }$ & 34 & 29 & 19 & 35 & \\
\hline $\mathrm{x}_{\text {máx }}$ & 70 & 70 & 56 & 69 & Cont. \\
\hline $\mathrm{p}$ & 0.314 & 0.916 & 0.846 & 0.368 & $\mathrm{z}=-1.146$ \\
\hline Teste Mann-Whitney & $\mathrm{z}=-1.089$ & $p=0.276$ & $\mathrm{z}=-2.434$ & $p=0.015$ & $p=0.252$ \\
\hline \multicolumn{6}{|l|}{ Suffering relational partner } \\
\hline $\bar{x}$ & 26.75 & 23.33 & 24.00 & 23.73 & Exp. \\
\hline $\mathrm{Md}$ & 27.50 & 22.00 & 25.50 & 22.00 & $\mathrm{z}=-2.809$ \\
\hline S & 6.05 & 5.62 & 7.89 & 4.37 & $p=0.005$ \\
\hline $\mathrm{x}_{\min }$ & 16 & 14 & 8 & 17 & \\
\hline $\mathrm{x}_{\text {máx }}$ & 35 & 35 & 35 & 31 & Cont. \\
\hline $\mathrm{p}$ & 0.458 & 0.392 & 0.657 & 0.443 & $\mathrm{z}=-0.926$ \\
\hline Teste Mann-Whitney & $z=-1.586$ & $p=0.113$ & $\mathrm{z}=-0.297$ & $p=0.766$ & $p=0.354$ \\
\hline \multicolumn{6}{|c|}{ Positive experiences of suffering } \\
\hline $\bar{x}$ & 16.00 & 16.67 & 17.31 & 17.53 & Exp. \\
\hline $\mathrm{Md}$ & 14.00 & 16.00 & 16.50 & 17.00 & $\mathrm{z}=-1.454$ \\
\hline $\mathrm{s}$ & 4.75 & 5.30 & 3.94 & 4.87 & $p=0.146$ \\
\hline $\mathrm{x}_{\min }$ & 10 & 7 & 12 & 8 & \\
\hline $\mathrm{x}_{\text {máx }}$ & 24 & 25 & 25 & 25 & $\begin{array}{c}\text { Cont. } \\
z=-2032\end{array}$ \\
\hline $\mathrm{p}$ & 0.019 & 0.904 & 0.095 & 0.891 & $\begin{array}{l}Z=-2.032 \\
p=0.042\end{array}$ \\
\hline Teste Mann-Whitney & $z=-0.695$ & $p=0.487$ & $z=-0.417$ & $p=0.677$ & \\
\hline \multicolumn{6}{|l|}{ Global suffering } \\
\hline $\bar{x}$ & 158.69 & 143.33 & 123.38 & 148.80 & \\
\hline $\mathrm{Md}$ & 164.50 & 144.00 & 122.50 & 157.00 & $\mathrm{z}=-3.517$ \\
\hline s & 31.47 & 30.49 & 32.07 & 28.34 & $p<0.001$ \\
\hline $\mathrm{x}_{\min }$ & 95 & 92 & 54 & 110 & Cont. \\
\hline $\mathrm{x}_{\text {máx }}$ & 206 & 192 & 165 & 190 & $\mathrm{z}=-2.556$ \\
\hline $\mathrm{p}$ & 0.174 & 0.715 & 0.379 & 0.119 & $p=0.011$ \\
\hline Teste Mann-Whitney & $z=-1.562$ & $p=0.118$ & $\mathrm{z}=-2.155$ & $p=0.030$ & \\
\hline
\end{tabular}


the second with higher values $(\bar{x}=42.9)$. In the study of Alves et al. [14] the average value was 43.53 .

Carqueja in 2009 [15] found statistically significant differences between the suffering and sex (women who percecionam more suffering, $p=0.003$ ), and between this dimension with anxiety $[\mathrm{r}=+0.676$ and $p<0.001]$ and with depression $[\mathrm{r}=+0.541$ and $p<0.001]$. Reveals that patients with pain in relation to cancer patients have a higher psychological suffering $(p<0.001)$. Some correlations are reflected in our study given that more than $80 \%$ of patients either in the experimental group, either in the control group and in both evaluations present pain and more than $50 \%$ have anxiety. However there are no significant differences between sexes.

In 2012, Alves et al. [14] add a positive correlation ( $\mathrm{rS}=+0.34$ e $p=0.039)$ between this dimension and expectations with the informal care primary care. This result can be related with the fear of the caretaker in the face of future expectations with the patient regarding the fears, concerns and availability and therefore matches the patient's cognitive changes related to the severity and consequences of disease.

As stated in Almeida [11], the symptoms observed in cancer patients are the obsession-compulsion (repetitive thoughts of restlessness and unease, behaviors and actions of hard to control), somatization, anxiety (nervousness and tension) and depression (loss of vital energy, lack of motivation, boredom easily), being influenced by the personality of the patient, sociodemographic factors, availability of resources, situational demands and the development phase of your disease. This author shows significant correlation between psychological suffering and ideation paranoide $(\mathrm{r}=+0.406$ e $p<0.05)$.

On the psychological suffering we can see not only cognitive but also emotional changes [9]-triggering instability, fears, fantasies, stress [16] [17], insomnia, suicidal ideations, humor, variable trends of abandonment [18] and mental-loss or threat with effort for obtaining meanings [1], difficulties in concentration, in memory and in the resolution of their problems [18].

As regards physical suffering, it was found above the intermediate values [18] at the stage of initial review, since the experimental group performed an average of $\bar{X}=22.94$ and the control group $\bar{X}=21.07$. These values can be associated with physical weakness that keeps us from being in contact with the envelope, with the world, with the loss of functional capacity is indispensable for the fulfilment of its functions, or any of your personal ability to autonomy within personal, family and professional, putting into question your personal dignity [4].

In Portugal this level of suffering has also been reported with levels above the intermediate value of the dimension. In the study of Gameiro [9] with an average of 37.73, Paulo study [12] with values in 22.32 Alves et al. [14] and in the Capela e Apóstolo [19] mentions an average of 20.55 physical suffering.

Unlike Sobral [13] found that although he had elevated to the four dimensions of suffering, physical suffering lower values $(\bar{x}=17.4)$, noting that the identification of the disease minimizes the impact of this kind of suffering. These values 
have been cited in the study of Ramos [10] that was found low levels of physical suffering $(\bar{x}=17.4)$ and Almeida [11] which gained an average 14.46 .

The results calculated in this study follow the ideology of Carqueja [15] which found the existence of a negative correlation between the physical suffering and the education $(p=0.042)$, where that mention more physical suffering are those patients who have until 6th grade. Since our sample features, in your majority, the first cycle of basic education (43.8\% in the experimental group and $40.0 \%$ in the control group) that may be a factor to justify the results of this dimension.

According to Carqueja [15], the physical suffering is correlated with anxiety ( $\mathrm{r}$ $=+0.499$ and $p<0.001)$, depression $(\mathrm{r}=+0.553$ and $p<0.001)$ and pain $(p<$ $0.001)$. This author distinguishes the pain of suffering that this is directed at a location of the body and this phenomenon is associated with the psychological, mental and soul, although reports that the pain is often the cause of suffering, designating him bodily suffering, as the body prevent's the well-being and be the center of frustration and conflict.

Likewise, we see in this study that in all these variables present higher values that the intermediate values, and can say that may be the cause of physical suffering explicit in the first assessment. The same author says that patients with external locus of control tend to suffer more physically $(p=0046)$.

With the intervention of the massage therapy patients showed significant improvement points, resulting in a decrease of $\bar{x}=5.94$, with an average value of $\bar{X}=17.00$ in the final evaluation of the experimental group. Denote that the result was conversely positive for the control group, and although no significant amounted to $\bar{X}=21.07$ for $\bar{X}=22.07$, increasing their average levels of physical suffering.

In terms of significance, the results in the final evaluation were distinct, showing values in the order of $p=0.021$. Analyzing the initial assessment with the final notes statistically differences being that the relevance of these results are based on the experimental group showing $p=0.001$, which translates to in this dimension of suffering the impact of massage therapy was beneficial bringing positive consequences.

These results agree with the study of Currin and Meister [20] which claimed that the sick after massage therapy had significantly decreased $(p<0.001)$ the physical discomfort.

In existential suffering has been the existence of values above the intermediate value 48, being that the assessment at an early stage in the experimental group performed an average of 53.94 and in the control group of 48.47 .

Several studies corroborate these values, namely Paulo [12] which featured an average of 52.64, Sobral [13] 47.68, values Alves et al. [14] with an average of 48.87 and the Capela and Apóstolo [19] with an average of 48.87. Contrary to what happens in the present study Almeida [11] found that the dimension to existential suffering presents below the recommended average value average with 39.2, as well as Ramos [10] who presented $\bar{X}=43.26$.

The calculated results of our study corroborate the Alves et al. [14] that in 
Portugal proved the existence of a correlation between this dimension and the education in the order of $p=0.025$, the groups with lower and higher education are the ones who tend to suffer more. This ideology is expressed in this work where it shows that patients who are more signs of suffering are those who have education of 1st cycle of basic education or degree, although the latter is less expressive than the last, showing values in percentage terms in order of $43.8 \%$ and $40.0 \%$ for the experimental and control group respectively. Therefore we have concluded that this may be a factor that justifies the results of this dimension.

Pinto [21] found that patients tend to be afraid of the future and that, contrary to expectation, are people who maintain your hope, regardless of being at a stage of advanced disease. Concluded that spirituality and hope $(\mathrm{r} p=+0.47$ e $p<$ $0.001)$ are interlinked, as well as the time of chemotherapy influences the levels of hope ( $\mathrm{r} p=-0.34 \mathrm{e} p<0.001)$ as a result of the awareness of the seriousness of the disease versus connection to life. At this stage, health professionals have relevance in the performance of your role as informants of the condition of the same clinic, assisting them to find the meaning of life based on feasible plans and reality.

To analyze the effects of massage therapy found that patients showed significant improvements $(p=0.001)$, because the benefit of massage in the experimental group made generates a decrease of $\bar{x}=14.81$, showing an average value in the second evaluation of $\bar{x}=39.1$.

As regards the control group ascertained that the result was opposite to the experimental, inversely, although not significant, positive however suffered a change of $x=48.47$ to $x=49.93$, thereby increasing their average levels of suffering in this dimension.

These results show that in this dimension to therapeutic massage has a positive impact, making this report a change/evolution advantageous, decreasing the values of levels of existential suffering. To corroborate this information studies submitted by Sobral [13] reveals that the personal control improves the existential suffering. In line with Currin and Meister [20] that, for your time, found a significant decrease in dimensions of suffering, particularly in emotional distress $(p<0.001)$.

When we talk about the social relational suffering, in quantitative terms and in the context of this dimension showed that the calculated values were above the intermediate value 21, taking into account that in the initial phase the experimental group performed an average of 26.75 and the Group of 23.33 control. Given this, we could explain the impact of these data by correlating them with the description of each item that is an integral part of this variable/dimension of suffering. In this dimension present items associated with the concern of loss of work; concern for the future, economic family concern.

Our patients, for your time, from 52.31 and experimental group 52.40 and checking respectively, concluding that these are of concern since they are in middle age, having as its main focus the problems generated by the items described above. To support this line of thought and by Alves et al. [14], it was 
noted that there is a negative correlation between age and this type of suffering (rs $=-0.35$ e $p=0.030$ ), the lower or higher the age of the patient, less socio- relational suffering and these author the showed an average of 23.66 in this dimension.

Paulo [12] showed that the average levels are presented with data in excess of the intermediate value of this dimension $(\bar{x}=52.64)$ and reports negative correlation between this dimension and the subjective experiences of suffering $\left(r_{s}=\right.$ -0.75 ). For your time Sobral [13] reported values of intensity $\bar{x}=24.92$, and symptomatic of the disease ID minimizes the socio-relational suffering.

It was noted that Capela and Apostolo [19] found that after the physical suffering the highest level of suffering was the relational partner $(x=23.66)$. In the present study this dimension appears in third place which is not to say that the same is not assigned expressiveness/importance, noting that even then the calculated values between the groups feature above the intermediate value and as such should be imposed minimization measures. The study of Sobral [13] revealed averages above the scale to 24.92 and values the Ramos [10] with 23.76, however in Gameiro [9] it was found below the intermediate values averaging 20.48 and Almeida [11] the average was of 20.79 .

These data are analysed according to some studies in Portugal, namely Almeida [11] that presents a correlation between socio-relational and suffering anxiety $(r=+0.193$ e $p<0.05)$ and the Carqueja [15] a relationship between the marital status and the relational partner suffering $(p=0.025)$, in which the mar$\mathrm{ried} /$ common law are the group that perceived more suffering. The latter refers to correlation with anxiety and depression $(\mathrm{r}=+0.463$ e $p<0.001 ; \mathrm{r}=+0.437$ e $p$ $<0.001)$. Taking into account that patients from our study, in the experimental group $(68.8 \%)$ as in $(80.0 \%)$ are married and have levels above the $50 \%$ for anxiety and depression, this may influence levels of suffering on this scale.

To evaluate the effects of before and after the intervention of massage therapy and their consequential effects was found the benefit of massage with respect to experimental group, with an average of 26.75 , i.e. it was found a reduction in levels of suffering in order of 2.75 showing a mean value at the stage of final assessment in order to 24.00 , and this significant difference $(p=0.005)$. Denotes-if there is an improvement with the following psychosocial effects: physical relaxation, relief of anxiety/stress, general feeling of well being with you and with the other, and sexual/relational stimuli such as describe Domenico and Wood. The same was not the case in the control group than in the initial evaluation showed a value of 23.33 and wavered in more negatively index rising 0.40 suffering for an average of 23.73 .

These results demonstrate that therapeutic massage has a beneficial impact, reducing the index of suffering on the part of patients in this dimension.

When we talk about the suffering, the word itself is already accompanied by a negative connotation. However, it is our goal to have positive experiences that can remove, now already we can see that suffering has a character of subjectivity associated with the significance that each patient gives the experience and ex- 
pression of their experiences. Having regard to the present study, we found that the values calculated between the groups reveal values above intermediate value 15 , in particular to the experimental group and 16.0016 .67 to the control group, which depict the presence of suffering.

In Portugal, by Alves et al. [14] it was found that the dimension that presented higher values was the positive experiences of suffering $(\bar{x}=17.29)$. At the same time, other studies showed levels above the intermediate value of the scale, namely Gameiro [9] with an average higher than the adapter with the value of 20.27, Paul [12] with $\bar{X}=52.64$, with $\bar{X}=15.6$, the Capela and Apóstolo [19] which found no median levels 17.29 and Ramos [10] with a mean of 17.94. Unlike Almeida [11] that revealed levels below the intermediate value with 13.1.

As the dimensions of the suffering described above, this dimension presents correlation between anxiety $(\mathrm{r}=-0.324$ and $p<0.01)$, depression $(\mathrm{r}=-0.493$ and $p<0.001)$ and pain $(p<0.001)$ (Carqueja, 2009) [15].

To evaluate the effects of before and after the intervention of massage therapy and its consequent effects, it was found with regard to the experimental group that this presents an average of 16.00 and that improves the value of 17.31, however was not statistically significant $(p=0146)$.

Unlike the experimental group increased the average values of 16.67 to 17.53, and this difference was statistically significant $(p=0042)$. Soon, the massage therapy had no benefit in this dimension of suffering.

As for the suffering, and in the overall initial assessment were emotionally debilitated, which in statistical terms the levels of positive experiences of grief reveal values above the intermediate dimension 132 with midpoint of 158.69 for the experimental group, although the experimental group presented lower values, with average 123.38 for the control group.

The levels of global suffering of the experimental group are in accordance with the study of Alves et al. [14] and Capela and Apóstolo [19] which highlighted the global average level of suffering for both 137.87. In accordance with the average values of the control group, Gameiro [9] shows low levels of global suffering ( $\bar{x}$ $=110.02)$ and Ramos [10] 125.27 values.

We could justify the above exposed data by Alves et al. study [14] that reports that in Portugal the impact of suffering global has a strong correlation with the level of education, in which the groups that suffer most are those who have smaller and larger qualifications. This ideology is strongly expressed in the present study, since in terms of qualifications it was found that a large part of the sample for the experimental group, held the first cycle of basic education, or lower level, showing data on the order of $50 \%$, although not so expressive, but not least, we got a percentage in the range of $12.5 \%$ for the sample with degree. As regards the monitoring group found that $60 \%$ of the sample had qualifications equal to or lower than the first cycle of basic education and that a 6.7 degree.

This ideological current is present in the current study. Both groups feature 
from 52.31 and 52.40, commonly known as the middle-age, with regard to the ages found that we had a balanced sample and for the experimental group had 8 participants being female, well as for the male.

In percentage terms it was noted that the vast majority of one of the groups was in marital status married/de facto United prowling values in order of $68.8 \%$ for the experimental group and $80 \%$ for the control group, with regard to the employment situation in the experimental group the data rode the $31.3 \%$ and $68.7 \%$ of inactive, with patients who were in a situation of reform presented the highest values around $50 \%$ compared to $13.3 \%$ of active control group situation.

Being our objective to evaluate the outcome of this pain through massage therapy, the emergence of signs of positive development with consequent improvement in patients, with the benefit of this intervention. With the incidence and application this action patients felt a relief under this dimension of suffering, with a decrease of the average rates in the experimental group in order of 35.31, showing the average initial assessment and the final assessment of 158.69 123.38.

In the light of what has come to be mirrored that the result was negative for the control group given that there was an increase in the average order of 5.47, evolving from $\bar{X}=143.33$ for $\bar{x}=148.00$.

These data demonstrate that massage therapy decreases pain levels for part of the cancer patients, having positive effects on the same.

\section{Conclusions}

The aim of this work was to verify if massage therapy had effects on suffering in the oncological patient, for such a research study based on the scientific method quasi-experimental. Two independent groups were established, called the experimental group, in which it was applied to massage therapy and nursing intervention to control who was not subjected to this application, the variable was evaluated suffering in two moments, namely initially sampling data and after 5 weeks of the completion of the first questionnaire.

The methodology described above allowed it to obtain results that proved the beneficial effect of massage therapy on the cancer patient in all the variables studied in the experimental group compared to the control group. In the suffering we see benefit in the psychological dimension $(p<0.001)$, physical $(p=0.001)$, existential $(p<0.001)$ in the relational partner $(p=0.005)$ and suffering $(p<$ $0.001)$.

In this way, as we can see the objectives initially set out to answer the initial question and "what effect of massage therapy on suffering in the oncological patient?" were globally assessed positively.

The results may contribute to anchoring in a structured way the role of the nurse, and develop strategies for the prevention and minimization of suffering in the oncological patient.

After the analysis of the results and all the accomplishment of work arise with 
alternatives suggestions and different directions, certainly also would produce data worthy of analysis, which are:

Carry out a study with the same design and with the evaluation of the same variables, but with longitudinal evaluation, which assessed, not only in the short term, but also the long-term effect of massage therapy;

Deepen the effect of massage therapy on the functional implications in cancer patient, especially in the sleep, anorexia, fatigue, functional capacity, among other functional changes described above.

We believe that, with this study, a remarkable research in the area of health, since, although we know that massage therapy is a nursing intervention and is a pharmacological treatment, we are also aware that it is not currently inserted in the practice of care. Therefore, in addition to terms contributed to a more sustained scientific knowledge on this subject, we found appropriate foster massage therapy and intervention, consequently optimize practice of care, quality and continuous improvement.

With the contribution and dissemination of this study, we consider to be an important factor in health policies, and may boost and encourage the implementation of this intervention in the different areas of care, such as hospital and community level. It is suggested the adoption of consultations open to the community.

\section{References}

[1] Gameiro, M. (1999) Sofrimento na doença. Quarteto Editora, Coimbra.

[2] Pessini, L. and Bertachini, L. (2004) Humanização e Cuidados Paliativos. Loyola, São Paulo.

[3] Gameiro, M. (2004) Estar Doente: Atribuição Pessoal de Significações. Referência, $12,35-44$.

[4] McIntyre, M. (2004) Perda e sofrimento na doença: contributo da psicologia da saúde. Psychologica, 35, 167-79.

[5] National Comprehensive Cancer Network. (16 de julho de 2016)

http://www.nccn.org/

Obtido de Clinical Practice Guidelines in Oncology: Distress Management: http://www.nccn.org/professionals/physician_gls/PDF/distress.pdf

[6] Cascais, A., Martini, J. and Almeida, P. (2008) Representações Sociais da Pessoa Estomizada sobre o Cancer. Revista Enfermagem, 16, 495-500.

[7] Cameron, L., Booth, R., Schlatter, M., Ziginskas, D. and Harman, J. (2007) Changes in Emotion Regulation and Psychological Adjustment Following Use of a Group Psychosocial Support Program for Women Recently Diagnosed with Breast Cancer. Psychooncology, 16, 171-80. https://doi.org/10.1002/pon.1050

[8] Ordem dos Enfermeiros (2012) Padrões de Qualidade dos Cuidados de Enfermagem. OE, Lisboa.

[9] Gameiro, M. (2000) IESSD: um instrumento para a abordagem do sofrimento na doença. Referência, 4, 57-65.

[10] Ramos, C. (2013) A Esperança e o Sofrimento no Doente Oncológico Paliativo. Dissertação de mestrado não publicada, Instituto Politécnico de Viana do Castelo, 
Viana do Castelo.

[11] Almeida, A. (2015) Experiência Subjetiva de Sofrimento na Doença e Sintomatologia Psicopatológica em Doentes Oncológicos. Dissertação de mestrado não publicada, Universidade de Trás-os-Montes e Alto Douro, Trás-os-Montes e Alto Douro.

[12] Paulo (2006) Vivências da dor e do Sofrimento na Pessoa com Doença Oncológica em Tratamento Paliativo. Dissertação de Mestradonão publicada, Universidade Aberta, Lisboa.

[13] Sobral, H. (2006) Experiências Subjectivas de Sofrimento em Doentes Oncológicos: Percepção da Doença e Religiosidade. Interacções, 11, 147-162.

[14] Alves, M., Jardim, M. and Freitas, O. (2012) Sofrimento do doente oncológico. Referência, 3, 115-24. https://doi.org/10.12707/RIII1217

[15] Carqueja, E. (2009) A prática religiosa e a percepção do sofrimento: Um estudo em doentes com cancro e em doentes com dor crónica. Cadernos de Saúde, 2, 7-40.

[16] Pereira, M. and Lopes, C. (2002) O doente oncológico e a sua familia. $1^{\text {a }}$ ed., Climepsi.

[17] Ryan, H., Schofield, P., Cockburn, J., Button, P., Tattersall, M., Turner, J., et al. (2005) How to Recognize and Manage Psychological Distress in Cancer Patients. European Journal of Cancer Care, 14, 7-15. https://doi.org/10.1111/j.1365-2354.2005.00482.x

[18] Barbosa, A. (2010) Espiritualidade. In: Barbosa, A. and Neto, I., Eds., Manual de Cuidados Paliativos, 2a ed., Núcleo de Cuidados Paliativos, Centro de Bioética da Faculdade de Medicina de Lisboa, Lisboa, 595-659.

[19] Capela, R. and Apóstolo, J. (2012) O sofrimento do doente oncológico em cuidados paliativos. Onco.news, 21, 41-48.

[20] Currin, J. and Meister, E. (2008) A Hospital-Based Intervention Using Massage to Reduce Distress among Oncology Patients. Cancer Nursing, 31, 214-21. https://doi.org/10.1097/01.NCC.0000305725.65345.f3

[21] Pinto, S. (2011) A Espiritualidade e a Esperança da Pessoa com Doença Oncológica: Estudo numa população de doentes em quimioterapia (Dissertação de mestrado não publicada). Faculdade de Medicina a Universidade do Porto, Porto. 